*Mestre em Direito Negocial pela Universidade Estadual de Londrina (UEL). Especialista em Direito Processual pela Universidade da Amazônia (UNIMA). Bacharel em Direito pela Universidade Estadual do Sudoeste da Bahia (UESB). Email: renatajauris@gmail.com

**Doutor em Direito pela Pontifícia Universidade Católica de São Paulo (PUC/SP). Mestre em Direito das Relações Sociais pela Universidade Estadual de Londrina (UEL). Bacharel em Direito pela Universidade Estadual de Londrina (UEL). Email: luizbel@uol.com.br

\section{AS MEDIDAS ESTRUTURANTES E A COMPATIBILIDADE COM O DIREITO PROCESSUAL BRASILEIRO}

\author{
THE POSSIBILITY OF APPLYING STRUCTURING INJUCTIONS IN \\ BRAZILIAN CIVIL PROCESSUAL LAW
}

\section{Renata Bolzan Jauris* Luiz Fernando Bellinetti**}

Como citar: JAURIS, Renata Bolzan; BELLINETTI, Luiz Fernando. As medidas estruturantes e a compatibilidade com o direito processual brasileiro. Scientia Iuris, Londrina, v. 24, n. 2, p. 64-80, jul. 2020. DOI: 10.5433/2178-8189.2020v24n2p64. ISSN: $2178-8189$.

Resumo: O presente trabalho trata da possibilidade de aplicação das medidas estruturantes no direito processual civil brasileiro. Com base em pesquisa bibliográfica visa identificar se o sistema normativo brasileiro, constitucional ou infraconstitucional é apto para a adoção das medidas estruturantes sem que haja afronta e contradição dentro do sistema. Para tanto, analisa os princípios constitucionais do acesso à justiça, a divisão das funções estatais, bem como os princípios da demanda e da correlação. Estuda ainda as inovações legislativas veiculadas no Código de Processo Civil de 2015, especialmente as cláusulas gerais processuais e o princípio da colaboração. Passa então ao estudo do artigo 21 da Lei de Introdução às Normas do Direito Brasileiro, que trouxe importante novidade quanto a adoção explícita da técnica da utilização das medidas estruturantes para a construção das decisões.

Palavras-chave: Medidas estruturantes. Efetividade. Implementação das decisões.

Abstract: This paper explores the possibility of applying
structuring injunctions in Brazilian civil procedural law. Utilizing
literature review, this study explores whether the Brazilian,
constitutional and infraconstitutional normative system is apt
for the adoption of structuring injunctions without contradicting
or affronting the current legal system. To this end, this article
analyzes the constitutional principles of access to justice, the
division of state functions, as well as the principles of demand
and correlation. It also studies legislative innovations of the 
Brazilian Code of Civil Procedure of 2015, specifically the general procedural clauses and the principle of collaboration. This study then goes on to study article 21 of the Law of Introduction to Norms of Brazilian Law, which adopts explicitly the use of structural measures in the judicial decision-making process.

Keywords: Structural injunctions. Efectiveness. Implementation of decisions. 


\section{INTRODUÇÃO}

As medidas estruturantes da decisão judicial são técnicas para a construção do comando decisório que, com o escopo de conferir efetividade, impõem respostas difusas ao litígio, de forma gradativa e orientada para o futuro, como forma de resolução do problema como um todo, evitando que a resposta dada ao litígio, por si, converta-se em um problema.

Com a utilização das medidas estruturantes, busca-se que a resposta jurídica dada à lide não seja inexequível, que a concretização não traga mais transtornos que a própria negativa do direito, ou que a decisão não se converta em nada mais do que palavras ante a ineficácia social intrínseca.

Nesse contexto, importante aferir a aptidão do direito processual brasileiro para a aplicação das medidas estruturantes. Para tanto, deve-se analisar as nuances históricas e conceituais das medidas estruturantes, a adaptação do instrumento ao eixo teórico e normativo vigente, bem como o formato que as decisões estruturais deverão assumir e os tipos de decisões em que são aplicáveis. Para tanto, será analisada nesse artigo a concepção que se tem de medidas estruturantes, a compatibilidade das medidas estruturantes com os princípios que regem o processo, tais como o princípio do acesso à justiça, da demanda e da correlação, a compatibilidade com o sistema de autocontrole do poder e as previsões legais que podem albergar a adoção, dentro do sistema processual, da sistemática das medidas estruturantes.

Utilizando-se do método lógico-dedutivo, o estudo demonstra a abertura no direito brasileiro da utilização das medidas estruturantes das decisões, seja por interpretação dos princípios constitucionais, das cláusulas gerais, e até mesmo em virtude de previsão normativa expressa.

\section{SOBRE AS MEDIDAS ESTRUTURANTES}

As medidas estruturantes ${ }^{1}$, decisões estruturais ${ }^{2}$ ou structural injunctions $^{3}$, consistem em diretivas para a concretização de um determinado direito adjudicado, por meio de uma decisão judicial. As medidas estruturantes são o resultado da atividade do Judiciário na solução de conflitos, que ao adjudicar o direito, o faz de maneira programada, gradual e prolongada no tempo, visando conferir efetividade e, ao mesmo tempo, neutralizar os impactos econômicos, culturais e sociais ocasionados pela implementação da decisão.

Quanto a conceituação das decisões estruturais, afirma Owen Fiss (2017, p. 25):

A adjudicação ${ }^{4}$ é o processo social por meio do qual os juízes dão significado aos valores públicos. A chamada reforma estrutural - o assunto desse artigo - é um tipo de adjudicação, distinto pelo caráter constitucional dos valores

\footnotetext{
$1{ }^{1}$ Designação empregada por Marco Felix Jobim (2013).

2 Terminologia empregada por Sérgio Cruz Arenhart (2013).

3 Denominação utilizada por Owen Fiss (1979) na tradução (FISS, 2017, p. 83) "reforma estrutural".

4 No sentido de atividade realizada pelo Poder Judiciário na solução de conflitos. A adjudicação, no emprego do vocábulo em língua inglesa, equivale a atribuir uma solução, dentre tantas possíveis, para a controvérsia (FISS, 2017, p. 25).
} 
públicos e, principalmente, pelo fato de envolver um embate entre o Judiciário e as burocracias estatais. O juiz tenta dar significado aos valores constitucionais na operacionalização dessas organizações. A reforma estrutural reconhece o caráter verdadeiramente burocrático do Estado moderno, adaptando formas de procedimentos tradicionais para a nova realidade social.

As medidas estruturantes têm a sua utilização indicada para as hipóteses em que, na fixação do comando decisório, as respostas diretas e imediatas não são as mais adequadas para a efetiva resolução do conflito e tem sua utilização recomendada em conflitos que demandem respostas difusas, com imposição gradativa e orientada para o futuro.

De acordo com Marco Félix Jobim (2013, p. 90-91) a aplicação das medidas estruturantes se dá nas hipóteses em que a justiça ou não da decisão, ante o seu conteúdo material, no exercício da função contramajoritária atribuída muitas vezes ao Poder Judiciário, seja questionada socialmente, e também em decisões que, por sua natureza, são irreversíveis e, por isso, precisam ser efetivadas.

A preocupação em garantir o atendimento das decisões judiciais, sobretudo aquelas que não se restringem a condenações em pagamento, é algo que ocorre no direito norte-americano há décadas, no entanto, inegavelmente se intensificou com o surgimento de demandas que visavam afastar a violação a direitos constitucionalmente garantidos (BAUERMANN, 2012, p. 53).

A preocupação relativa a criação de mecanismos para o atendimento das deliberações judiciais como forma de garantir a dignidade da justiça e o respeito ao Poder Judiciário se intensificou com o julgamento do caso Brown v. Board of Education of Topeka (BAUERMANN, 2012, p. 53-54). O leading case é considerado o marco das ações estruturais e gerou a alteração de paradigmas quanto à forma de julgar dos tribunais americanos; quanto à sociedade americana como um todo; e quanto à aplicação de meios executórios inovadores, dirigidos para os governantes e para a população (BAUERMANN, 2012, p. 54).

O caso Brown v. Board of Education of Topeka tratou do sistema de segregação racial conhecido como separate but equal o qual, na época da decisão, estava vigente há aproximadamente dois séculos e é considerado paradigmático, pois foi o marco do fim da doutrina do separate but equal ao reconhecer aos negros o direito de frequentarem as mesmas escolas que os brancos, alterando a interpretação dada à Décima Quarta Emenda à Constituição dos Estados Unidos da América (JOBIM, 2013, p. 76-77).

Mais que um marco na luta pela igualdade racial nos Estados Unidos da América, a decisão constituiu um avanço em busca da efetividade das decisões. A Corte não se restringiu ao reconhecimento do direito dos negros de ingressarem nas escolas reservadas aos brancos, mas também determinou uma aplicação em larga escala de uma política pública de dessegregação ao abarcar, inclusive, alunos e escolas que não estavam envolvidos diretamente no caso (MORO, 2004, p. 40).

Para a formação da decisão proferida no caso Brown v. Board of Education of Topeka, na busca de decisões fundadas na racionalidade, factíveis e efetivas, foi preciso diálogo institucional e ampliação da cognição judicial. E, mesmo diante de toda a fundamentação interdisciplinar, na 
decisão proferida em 1954, a Corte não estabeleceu a forma de implementação do julgado - o que somente veio a ocorrer quase um ano depois, quando foi determinado o cumprimento pelas autoridades escolares, sob a supervisão das instâncias federais inferiores. E, a despeito de toda essa preparação para a efetivação do julgado, foi inevitável a reação maciça à implementação, principalmente por parte dos estados sulistas (MORO, 2004, p. 40-41).

Ao se preocuparem com a realidade existente no momento em que a decisão é proferida, as medidas estruturantes, privilegiam a visão do julgado como um instrumento para a efetividade:

Daí se percebe que a garantia da efetividade do provimento é uma das maiores, senão a maior, preocupação dessas decisões, que buscam privilegiar a solução mais ampla, que alcance resultados que possam beneficiar toda a coletividade, atendendo as suas necessidades (CASTELO, 2017, p. 327).

A maleabilidade, a efetivação gradual, progressiva e dialogada são características das decisões proferidas de forma estrutural eis que se baseiam na noção de que a vida social é afetada de forma significativa por decisões que promovam mudanças, especialmente quando tais mudanças envolvem valores constitucionais e, para tanto, mister se faz uma alteração prévia nos próprios arranjos institucionais existentes.

Fredie Didier Júnior, Rafael Alexandria de Oliveira e Hermes Zaneti Júnior (2017, p. 355), em sentido semelhante, conceituam:

A decisão estrutural (structural injunction) é, pois, aquela que busca implantar uma reforma estrutural (structural reform) em um ente, organização ou instituição, com o objetivo de concretizar um direito fundamental, realizar uma determinada política pública ou resolver litígios complexos. Por isso, o processo em que ela se constrói é chamado de processo estrutural. Parte-se da premissa de que a ameaça ou lesão que as organizações burocráticas representam para a efetividade das normas constitucionais não pode ser eliminada sem que tais organizações sejam reconstruídas.

As medidas estruturantes visam a solução de uma lide multifacetada e que envolva a multiplicidade de interesses, saindo da formatação bipolarizada do litígio tradicional, para uma lógica em que há multiplicidade de sujeitos e formação de diversos núcleos de posições e opiniões, pontos de vista concorrentes ou divergentes (ARENHART, 2017, p. 425-426).

Diante de tais características, nota-se que há uma inadequação da estrutura processual tradicionalmente prevista para lidar com o processo estrutural. As raízes liberais que marcam a estrutura do processo traçam a atuação do magistrado unicamente nos estritos termos da legislação, porém, a realidade econômica e social gera o surgimento de questões mais complexas. A necessidade de adequação no plano processual, a alteração dos parâmetros tradicionais, a maleabilidade ao magistrado são consectários da resolução das lides mais complexas para que se alcance a efetividade. 


\section{AS MEDIDAS ESTRUTURANTES NO DIREITO BRASILEIRO}

Os principais óbices, apontados pela doutrina, à aplicação das medidas estruturantes existentes no processo civil brasileiro, são os limites impostos pelo princípio da demanda, a inadequação das medidas estruturantes ao sistema de controle do poder estatal e a ausência de previsão normativa, no sistema brasileiro, suficiente para lastrear a aplicação do instituto.

É inegável que o direito processual civil brasileiro se assenta numa perspectiva individualista, razão pela qual os estudos e conceitos dos principais institutos tem como arcabouço o processo individual. No entanto, a visão de processo pautada nos clássicos valores liberais, com promessas de tutelas jurisdicionais vocacionadas ao princípio da demanda e a estreita correlação entre o pedido e a sentença, a despeito de satisfatória na resolução dos litígios individuais e que envolvam tão somente o direito privado, mostra-se distanciada da realidade social.

Quando surge a necessidade de que o processo seja meio de assegurar o exercício em concreto de importantes direitos fundamentais e, consequentemente ser meio de inserção de indivíduos na vida social, esse processo com raízes liberais mostra-se inadequado e distante da relação com os direitos materiais. As medidas estruturantes surgem justamente como uma das maneiras de conciliar as necessidades sociais de efetivação com a visão liberalista do processo.

\subsection{Do princípio da demanda}

Reflexo do processo pautado em uma visão liberal, tem-se o princípio da demanda. Também conhecido como princípio da adstrição, este princípio traz em si a ideia de que é o autor quem decide contra quem litigará, o que pedirá contra o seu adversário e ainda com fundamento em qual causa de pedir, deduzirá a pretensão. Do princípio da correlação ou da congruência, a seu turno, como uma consequência do princípio da demanda, infere-se que ao magistrado é defeso proferir sentença ultra, extra ou citra petita, ou seja, dar ao autor mais do que ele pediu, algo diverso do que ele pediu, ou eximir-se de julgar o pedido ou algum dos pedidos (BENEDUZI, 2016, p. 292-293).

Os princípios da demanda e da correlação estão previstos nos artigos 141 e 492 do Código de Processo Civil que também traz a consequência para o desrespeito a tais princípios, qual seja, a nulidade da sentença que concede a mais ou diferente daquilo que foi pedido, que está fundada em causa de pedir não narrada pelo autor, que atinge terceiros que não participaram do processo, ou que não julga a demanda relativamente a certos demandantes (NEVES, 2016, p. 762-763).

Os princípios da adstrição e da congruência, a despeito de terem seu fundamento nas garantias do contraditório e da ampla defesa, comportam exceções: nos pedidos implícitos quando ao juiz é dado conceder aquilo que não está expressamente pedido pelo autor; nos casos em que se aplica a fungibilidade, tais como nas ações possessórias e cautelares em que se permite ao magistrado conceder tutela diversa daquela requerida; e, nas demandas que tenham como objeto uma obrigação de fazer e/ou não fazer, desde que a tutela gere um resultado prático equivalente ao 
do adimplemento da obrigação (NEVES, 2016, p. 764).

Ainda sob a égide do Código de Processo Civil de 1973, Luiz Guilherme Marinoni (2006, p. 249), afirmava que para a efetiva tutela dos direitos era necessário dar mais poderes ao juiz, com fincas na quebra do princípio da tipicidade das formas executivas e na concentração da execução no processo de conhecimento, em face da superação da ideia de absoluta congruência entre o pedido e a sentença.

Diante da multiplicidade de interesses que se inter-relacionam sobre o objeto do litígio estrutural e da intervenção judicial voltada para alcançar metas de natureza continuada e que possam ser continuamente revistas não se pode conceber a causa de pedir como completamente delineada eis que baseada, muitas vezes, numa prospectiva do porvir.

Nas ações estruturais as necessidades de proteção são mutáveis, e o que é suficiente e compatível em um determinado momento, muito frequentemente, poderá não ser em outra ocasião (ARENHART, 2013, p. 389-410). Assim, é muito difícil que o autor da demanda possa, já ao redigir a petição inicial, ter a exata dimensão daquilo que no futuro será necessário para atender, de forma adequada, o direito protegido. Ainda que o autor consiga antecipar completamente as necessidades de proteção do direito tutelado, aferir que estas medidas foram suficientes somente será possível ao final do processo. A atenuação do princípio da demanda, desta feita, é necessária para a construção das medidas estruturantes.

De acordo com Owen Fiss (2017, p. 41) o modelo estrutural envolve o distanciamento de um modelo ideal, de um protótipo ou ação judicial "modelo", de uma forma ideal com qual todas as ações judiciais serão comparadas, pois o modelo existe como parte de uma tríade individualista. A lógica processual inerente às ações estruturantes, portanto, não se coaduna a uma interpretação restrita do princípio da congruência e da adstrição:

A decisão estrutural que se quer impor por meio da atenuação do princípio da demanda supera o formalismo processual, dado seu caráter instrumental. Têm elas como objetivo maior, ao ir de encontro com a conhecida burocracia estatal, não apenas eliminar as mais variadas violações a direitos mas também efetivar valores tão caros e fundamentais à sociedade, que normalmente são negligenciados pelo poder público. Essas decisões judiciais querem reestruturar determinadas entidades estatais para convertê-las de acordo com a Constituição. E é exatamente nessa órbita de ideias que deverá o operador do direito transitar, isto é, a de que o processo civil somente produzirá legítimas decisões se estiver de acordo não apenas com o direito infraconstitucional mas também e, principalmente, com os valores e direitos fundamentais incorporados pela Constituição Federal (PINTO, 2017, p. 386).

Uma decisão principal, numa ação estrutural, ensejará o surgimento e a sucessão de outras decisões as quais somente podem ser tomadas dependendo do resultado do cumprimento das decisões anteriores. Não há como imaginar que as medidas estruturantes se submetam rigidamente aos princípios da demanda e da correlação ${ }^{5}$ ante a fluidez, mutabilidade e complexidade dos litígios

5 De acordo Renato Beneduzi (2016, p. 292-293) o princípio da demanda, também conhecido como princípio da 
que as envolvem ${ }^{6}$. O direito a obtenção da solução de mérito das demandas não deve ser entendido apenas como o direito à solução do problema em abstrato, mas como direito a que o provimento jurisdicional seja apto a transformar realidade. Nas ações estruturais, o alcance das mudanças e até mesmo as mudanças que lhes são caras, são mutáveis, fluidas, incompatíveis com o princípio da demanda e da correlação rigidamente estabelecidos.

A adequação das medidas estruturantes no processo tradicional exige que os princípios da demanda e da correlação sejam apreciados de forma maleável ${ }^{7}$, pois apenas o bem da vida protegido é que pode ser delineado prima facie, sem que sejam descritos o provimento jurisdicional pretendido, todas as pessoas atingidas pela ordem e todos os fatos que envolvem a causa de pedir. Desta feita, considera-se que há mitigação a tais princípios e a mitigação é tolerada pelo direito processual ante a primazia da efetividade.

\subsection{Sistema de autocontrole e medidas estruturantes}

É inquestionável a necessidade de um sistema de autocontrole do poder à medida em que é crucial prevenir o arbítrio e proteger a liberdade, sem podar o pleno desenvolvimento individual e social. A divisão baseada nas funções estatais de legislar, administrar e julgar, não implica em necessidade de uma separação estanque entre os poderes, mas sim em desmembramento das funções, que surge, inclusive, como um dos principais mecanismos de controle.

Uma das finalidades do sistema de separação de poderes é conferir caráter democrático do Estado e a liberdade dos indivíduos. Ocorre que as plenas liberdades ficaram restritas a poucos ao passo que criou-se uma sociedade imiscuída por injustiças sociais. Nota-se, portanto, que "esse sistema falhou fragorosamente em suas finalidades, levando a uma profunda reflexão com vistas ao seu aperfeiçoamento" (BELLINETTI, 1997, p. 167) e, tal aperfeiçoamento deve se dar justamente através da ampliação dos meios de controle da sociedade sobre o poder estatal.

Em nível organizativo do Estado, a repartição do exercício das funções, tem como adstrição, preconiza que é o autor quem decide contra quem litigará, o que pedirá contra o seu adversário e ainda com fundamento em qual causa de pedir, deduzirá a pretensão. O autor afirma ainda que o princípio da correlação ou da congruência, sendo uma consequência do princípio da demanda, implica ao magistrado a proibição de proferir sentença ultra, extra ou citra petita, ou seja, dar ao autor mais do que ele pediu, algo diverso do que ele pediu, ou eximir-se de julgar o pedido ou algum dos pedidos.

6 Sobre a especificidade do processo estrutural é importante a posição de Marco Félix Jobim (2017, p. 459) que defende a existência de uma teoria do processo ou litígio estrutural: “Acredito que, nesse momento ainda de reflexão, tendo a responder que não, ou seja, o processo estrutural, em que pese poder se utilizar dos institutos inerentes aos processos coletivos em geral e ao processo civil, deve, até em razão de se apresentar como algo ainda muito novo em solo brasileiro, ter uma base teórica própria, que possa responder aquela pergunta inicialmente feita e que causa extrema angústia àqueles que se dedicam a pensar sobre o tempo, assim como outras, como: o Poder Judiciário pode implementar técnicas sem agredir a teoria da tripartição dos poderes? Não é conceder demasiado poder aos juízes a possibilidade de expedir técnicas estruturantes? Talvez as respostas passem pela construção de uma teoria própria ao litígio estrutural".

7 O Código de Processo Civil traz a previsão dos princípios da demanda e da correlação nos artigos 141 e 492 e a consequência para o desrespeito a tais princípios é a nulidade da sentença que concede mais ou diferente do que foi pedido, que está fundada em causa de pedir não narrada pelo autor, que atinge terceiros que não participaram do processo, ou que não julga a demanda relativamente a certos demandantes (NEVES, 2016, p. 762-763). Ocorre que a despeito dos princípios da adstrição e da congruência terem seu fundamento nas garantias do contraditório e ampla defesa, comportam exceções, tais como nos pedidos implícitos quando ao juiz é dado conceder aquilo que não está expressamente pedido pelo autor; nos casos em que se aplica a fungibilidade, tais como nas ações possessórias e cautelares em que se permite ao magistrado conceder tutela diversa daquela requerida; e, nas demandas que tenham como objeto uma obrigação de fazer e/ou não fazer, desde que a tutela gere um resultado prático equivalente ao do adimplemento da obrigação (NEVES, 2016, p. 764). 
finalidade a criação de um exercício moderado e controlado das funções estatais. Ocorre que as funções estatais politicamente relevantes se desenvolvem em inúmeros setores e surgem sempre sob novos formatos. Assim, o controle do exercício dessas funções, igualmente, precisa assumir novas formas (ZIPPELIUS, 1997, p. 401).

Em face da visão do poder do Estado como uno e indivisível e da divisão de funções na organização estatal entre o Judiciário, Executivo e Legislativo não como separação entre poderes, mas sim como uma divisão pragmática, nota-se a consonância entre as medidas estruturantes da decisão judicial e a ideia de divisão das funções para aperfeiçoamento do autocontrole do poder estatal.

A divisão das funções estatais passa a ser vista como interpenetração entre as funções e não em efetiva separação. De tal modo, pode-se considerar que nas medidas estruturantes das decisões judiciais, quando se fala na aplicação em face do poder público, não significa que o Poder Judiciário estaria se imiscuindo das funções do Poder Executivo ou até nas do Legislativo, mas sim que está em pauta dos mecanismos de controle do poder estatal, assim, com perfeita adequação ao sistema constitucional. Obtempere-se que o Supremo Tribunal Federal tem decidido ${ }^{8}$ que o argumento de ofensa à "separação" dos poderes não é justificativa capaz de afastar a possibilidade do Poder Judiciário apreciar pretensão que examine direito fundamental social.

Assim, o que se observa é que as medidas estruturantes representam, a seu turno, um formato diferenciado e aprimorado do controle das funções estatais.

\subsection{Previsão normativa das medidas estruturantes no direito brasileiro}

$\mathrm{O}$ acesso à justiça - que conta com previsão constitucional expressa no artigo $5^{\circ}$, inciso XXXV da Constituição da República de 1988, através da redação "a lei não excluirá da apreciação do Poder Judiciário lesão ou ameaça a direito"- erige, por meio de uma cláusula aberta de controle judicial, como garantia fundamental a inafastabilidade da jurisdição, o que assegura o direito à tutela jurisdicional adequada, efetiva e tempestiva.

O artigo $3^{\circ}$ do Código de Processo Civil de 2015 repete a redação constitucional e consagra a mesma perspectiva, num viés processual, o que garante que qualquer cidadão tem direito a que a sua pretensão seja analisada pelo Poder Judiciário (BRASIL, 2015a). Acrescentam Luiz Guilherme Marinoni e Daniel Mitidiero (2016, p. 108-109) que, na redação desse dispositivo, o legislador infraconstitucional perdeu a oportunidade de explicitar o sentido do acesso à justiça como direito à tutela adequada, efetiva e tempestiva dos direitos. E, em outro termo, de forma explícita, nos parágrafos, procurou estabelecer um sistema de justiça multiportas no Brasil, buscando adaptar a prestação da justiça às especificidades do direito material.

$\mathrm{O}$ acesso à justiça deve ser visto, sobretudo, sob um espectro qualitativo, no sentido de se garantir efetividade à tutela dos direitos. Nesse sentido, fala-se no uso planejado do princípio do

8 Recurso Extraordinário 592.581/RS, rel. Min. Ricardo Lewandowski, DJe 13.08.2015. Órgão Julgador: Tribunal Pleno. (BRASIL, 2015b). 
acesso à justiça, visando conferir uma tutela universal, material e efetiva a direitos que vêm sendo desrespeitados ou negados (VICENZA; ALVES; REZENDE; 2016, p. 222).

Grande enfoque deve ser conferido, portanto, às formas de tutela jurisdicional adequadas e aos consectários processuais. Assim, a obtenção de resultados legítimos e eficientes para o cidadão que busca o acesso à justiça revigorado pela concepção de um Estado Constitucional Democrático é primordial a partir da percepção dos impactos que têm as concepções dinâmicas dos direitos fundamentais para o direito processual (NUNES, 2012, p. 258). O Estado deixa de ser visto apenas como protetor dos direitos fundamentais, e passa assumir o papel de ente que age positivamente no sentido de promovê-los.

A necessidade de implementação da tutela adequada aos direitos faz com que as medidas estruturantes das decisões judiciais, entendidas estas como mecanismos de busca da tutela adequada ao direito, desta feita, sigam ao encontro da visão que se deve ter de acesso à justiça, seja através da busca de soluções do direito material controvertido em casos paradigmáticos, bem como de soluções de implementação em litígios estratégicos.

O processo passa a ser visto como a estrutura de formação das decisões e de promoção dos direitos fundamentais. Assim, é preciso reconhecer a importância da estrutura multifacetada, coparticipativa e policêntrica que deve ser conferida ao processo, típica do processo estrutural, como algo essencial para a efetividade das decisões e consequente concretização do acesso à justiça.

A seu turno, o Código de Processo Civil de 2015, oferece guarida para as medidas estruturantes ao passo que, em seu texto, consagra cláusulas gerais as quais conferem mobilidade ao sistema legal. As cláusulas gerais têm função instrumental, eis que vivificam o conteúdo da norma e abrandam a rigidez conceitual (NERY JÚNIOR; NERY, 2017, p. 292-293) e assim o conteúdo valorativo de uma norma poderá se adaptar às necessidades e mudanças sociais.

A abertura semântica conferida ao órgão julgador, diante da presença, por exemplo, das cláusulas gerais executivas (artigo 139, IV, artigo 297 e artigo 536, parágrafo $1^{\circ}$ do Código de Processo Civil de 2015), do poder geral de cautela (artigo 301 do Código de Processo Civil de 2015), da cláusula geral do abuso do direito do exequente (artigo 805 do Código de Processo Civil de 2015), da cláusula geral de adequação do processo e da decisão em jurisdição voluntária (artigo 723, parágrafo único do Código de Processo Civil de 2015) e da cláusula geral de promoção pelo Estado da autocomposição (artigo $3^{\circ}$, parágrafo $1^{\circ}$ do Código de Processo Civil de 2015), já possibilitam por si, a utilização das medidas estruturantes como forma de efetivação da decisão judicial (BRASIL, 2015a).

O Código de Processo Civil de 2015, ao inserir como cláusula geral, no artigo $6^{\circ}$, a colaboração, instituiu como linhas centrais para a organização do processo a construção de um modelo cooperativo, baseado no princípio da colaboração. A colaboração, como modelo e como princípio, portanto, passa a formar um eixo sistemático a partir do qual o processo justo se estrutura, o que gera uma mudança epistemológica quanto à visão do processo (MARINONI; MITIDIERO, 2016, p. 146). 
Para Luiz Guilherme Marinoni e Daniel Mitidiero (2016, p. 148-150) a colaboração, vista como modelo, se compõe a partir de pressupostos culturais que podem ser concebidos sob os ângulos social, lógico e ético: para o ângulo social a sociedade é vista como um empreendimento de cooperação entre os seus membros, para a obtenção de proveito mútuo e do Estado como ente vocacionado a promover a tutela dos direitos; sob o ângulo lógico, a colaboração faz com que as normas jurídicas sejam vistas como o resultado da colaboração entre o legislador e o juiz; e, sob o prisma ético, o processo colaborativo seria um processo orientado pela busca da verdade. Assim, o processo colaborativo, deixa espaço para a alteração da postura dos magistrados na própria maneira de conduzir o processo:

O juiz do processo cooperativo é um juiz isonômico na sua condução e assimétrico apenas quando impõe suas decisões. Desempenha duplo papel: é paritário no diálogo e assimétrico na decisão. A paridade na sua condução está em que, embora dirija processual e materialmente o processo, atuando ativamente, fálo de maneira dialogal (art. 139, CPC). Vale dizer: o juiz participa do processo colhendo a impressão das partes a respeito dos seus rumos, possibilitando assim a influência dessas na formação de suas decisões (de modo que o iudicium acabe sendo efetivamente um ato trium personarum, como se entendeu ao longo de toda a praxe do jus commune) (MARINONI; MITIDIERO, 2016, p. 149).

A decisão judicial passa a ser entendida como o produto de um efetivo diálogo numa comunidade de trabalho formada por todos os sujeitos do processo, e não mais algo elaborado de forma solitária pelo juiz:

A gestão do procedimento de elaboração da decisão judicial é difusa, já que o provimento é o resultado da manifestação de vários núcleos de participação, ao mesmo tempo em que os sujeitos processuais - inclusive as partes - cooperam com a condução do processo (policentrismo processual) (FRANCO, 2015, p. 113).

A consagração da cláusula geral de negociação processual, resultante da adoção de um modelo cooperativo de processo, gera reflexos positivos para a aceitação da aplicabilidade, no direito brasileiro, das medidas estruturantes das decisões judiciais. Marco Félix Jobim (2013, p. 197), afirmou, durante a vigência do Código de Processo Civil de 1973, que o artigo 461 também seria um permissivo legal para a estruturação das decisões judiciais pois prevê a prevalência da tutela específica das obrigações ou a concessão de providências que assegurem resultado prático equivalente nas ações que tenham por objeto as prestações de fazer ou não fazer. Observe-se da redação dos artigos 497, 499 e 500 do Código de Processo Civil de 2015 que o legislador repetiu a preferência pela tutela específica ou equivalente ao resultado prático e, portanto, manteve o permissivo enumerado por Marco Félix Jobim.

O processo estrutural se manifesta com nuances próprias, diferenciadas das nuances liberais que permeiam o Processo Civil brasileiro e, a despeito das inovações legislativas elencadas, 
o mais importante é o indicativo de mudança epistemológica.

Nesse sentido, um grande avanço que se pode observar quanto a possibilidade de aplicação no direito brasileiro das medidas estruturantes, é a inovação legislativa trazida pela Lei $\mathrm{n}^{\mathrm{o}}$ 13.655/2018 (BRASIL, 2018) que inclui dispositivos ao Decreto-Lei $\mathrm{n}^{\circ}$ 4.657/1942 (Lei de Introdução às Normas do Direito Brasileiro) (BRASIL, 1942). Esta lei trouxe a previsão expressa da necessidade de que as decisões que decretem a invalidação de ato, contrato, ajuste, processo ou norma administrativa indiquem de modo expresso suas consequências jurídicas e administrativas, bem como as condições para que a regularização ocorra de modo proporcional e equânime e sem prejuízo aos interesses gerais, sem que se imponha aos sujeitos envolvidos ônus ou perdas anormais. Trata-se de evidente comando normativo em que o julgador é obrigado a aplicar as medidas estruturantes nas decisões.

Obtempere que o emprego do processo estrutural nem sempre surge em razão da necessidade de solucionar uma lide complexa. O valor constitucional protegido pela ação (proteção ao meio ambiente e saúde, nas hipóteses) em si não é controvertido ou representa um avanço de mentalidade quanto à interpretação de direitos fundamentais, porém, a lide exige a aplicação da estruturação, não pelo reconhecimento do direito em si, mas pelos impactos sociais da implementação. O processo estrutural aqui buscou a efetividade dos direitos fundamentais diante da identificação das falhas estruturais presentes no mecanismo de proteção a tais direitos, tentando corrigir os equívocos geradores de agressão, in casu, ao meio ambiente e saúde.

Sérgio Cruz Arenhart (2013, p. 389-410) afirma que as decisões estruturais "são uma necessidade para qualquer sistema processual em que se admita a intervenção em políticas públicas ou grandes inserções em relações privadas. Assim, o campo de aplicação das decisões estruturais, a despeito de ser mais fértil na seara que envolve o direito público, a ele não se restringe.

Algumas manifestações legislativas que exemplificam a aplicabilidade das medidas estruturantes no campo do direito privado foram compiladas por Sérgio Cruz Arenhart (2013):

No campo privado, aliás, há norma expressa que admite a criação de decisões microinstitucionais. Especificamente para a tutela do direito à concorrência, a Lei n. 12.529/11 (mas, mesmo antes dela, a Lei n. 8.884/94) contém diversos instrumentos que, judicial ou extrajudicialmente, autorizam o emprego de medidas que interferem em atos de dominação econômica e permitem a criação de mecanismos de acompanhamento do cumprimento dessas decisões. Assim, por exemplo, o art. 38, inc. VII, dessa lei (e, de modo idêntico, o faz o art.61, § $2^{\circ}$, inc. VI), prevê como sanção à prática de atos que violam a ordem econômica a adoção de "qualquer outro ato ou providência necessários para a eliminação dos efeitos nocivos à ordem econômica". O art. 52, da lei, a seu turno, estabelece que "o cumprimento das decisões do Tribunal [administrativo] e de compromissos e acordos firmados nos termos desta Lei poderá, a critério do Tribunal, ser fiscalizado pela Superintendência-Geral, com o respectivo encaminhamento dos autos, após a decisão final do Tribunal". Enfim, prevê a lei, em diversos dispositivos (arts. 96 e 102 a 111), a possibilidade de intervenção judicial em empresa, que poderá ter seu papel limitado ao acompanhamento do cumprimento da decisão jurisdicional, ou ter função mais ampla, chegando até ao extremo de 
legitimar o interventor a assumir a administração da empresa (art. 107, § $2^{\circ}$, da lei) (ARENHART, 2013, p. 389-410)

Em outro giro, dentre os julgamentos proferidos pelo Supremo Tribunal Federal que empregaram as medidas estruturantes, Marco Félix Jobim (2013, p. 165-171) destaca as ações que envolvem a demarcação das terras indígenas conhecida como caso Raposa Serra do Sol${ }^{9}$, e o mandado de injunção que discute o direito constitucional de greve dos servidores públicos civis ${ }^{10}$.

Sérgio Cruz Arenhart (2015, p. 221) aponta como um protótipo de processo estrutural no direito brasileiro as decisões que outorgam determinado medicamento a doentes necessitados e fixam, fora dos liames definidos pelo pedido, condições e limites para o fornecimento e que - inobstante tratarem-se de sentença condicional, portanto, nula às vistas do processo clássico a necessidade de comprovação posterior da necessidade do medicamento é consectário lógico; bem como as hipóteses de ação coletiva ambiental, em que os magistrados têm condicionado a modificação na área afetada a prévia manifestação ou orientação do órgão ambiental competente, ou, ainda a de condicionar a prática de certos atos à prévia autorização do órgão ambiental de fiscalização ${ }^{11}$.

Nota-se, portanto, que o direito brasileiro demonstra abertura para a aplicação das medidas estruturantes, tanto em âmbito constitucional quanto na legislação infraconstitucional, não apenas nas hipóteses de litígios estratégicos ou de impacto, ou nas hipóteses em que a divergência quanto ao tema na sociedade é intensa, o que impediria uma solução única, pronta e acabada, mas também quando através do processo, busca-se a identificação das falhas estruturais nos mecanismos de outorga dos direitos fundamentais.

O que se observa, portanto, é uma mudança de eixo estrutural do processo civil, e do próprio direito brasileiro, em que se verifica o Processo Estrutural como técnica idônea para a construção, implementação e efetivação das decisões judiciais, seja através da previsão constitucional do acesso à justiça, da possibilidade de utilização das medidas estruturantes como forma de aperfeiçoamento ao sistema de autocontrole da administração, bem como da estrutura colaborativa formada pelas cláusulas gerais inseridas no Código de Processo Civil de 2015, e da previsão expressa inserida na Lei de Introdução às Normas do Direito Brasileiro.

9 Trata-se da ação popular tombada sob o número 3.388/RR, inteiro teor disponível em Brasil (2019). No caso Raposa Serra do Sol, quanto as medidas estruturantes, o que importa é a parte pertinente ao voto do Ministro Carlos Alberto Menezes Direito, que por técnica de decisão passou a fazer parte integrante do acórdão, especialmente quanto a imposição das 18 (dezoito) restrições ao exercício do direito dos indígenas, as quais constam do comando decisório do referido voto.

10 Refere-se ao Mandado de Injunção tombado sob o número 708, ementa disponível em Brasil (2008).

11 A aplicação do processo estrutural nas ações que discutem proteção ao meio ambiente é exemplificada através da ação civil pública (autos n ${ }^{\circ}$ 93.8000533-4) ajuizado na Justiça Federal de Criciúma que na sentença impôs aos réus oferecer, em seis meses, um projeto de recuperação da região, com cronograma mensal de etapas a serem executadas, compreendendo as mais diversas obras para o fim de amenizar os danos sofridos pela população dos municípios em que ocorriam a extração e beneficiamento do carvão. Foram determinadas ainda multa coercitiva, impostas medidas de sub-rogação, bem como a obrigação das mineradoras adequarem a conduta às normas de proteção ambiental. Aos órgãos de fiscalização de mineração e de proteção ambiental foi determinado o dever de apresentar relatórios circunstanciados da fiscalização em todas as minas da região. O Ministério Público teria o dever de opinar quanto aos relatórios apresentados, os quais deveriam ser submetidos ao crivo do Judiciário (ARENHART, 2015, p. 222). 


\section{CONCLUSÃO}

Uma sociedade complexa e em intensa transformação, faz com que surjam conflitos igualmente complexos e mutáveis. Nesse contexto, o Direito precisa trazer soluções a tais conflitos, e soluções que sejam efetivas. A estrutura processual tradicional, de raízes liberais e individualistas mostra-se insuficiente para tratar tais conflitos.

Nesse contexto, surgem as medidas estruturantes, que consistem em diretivas para a concretização de um direito adjudicado através de uma decisão judicial que o faz de forma programada, gradual e prolongada no tempo, visando conferir efetividade e adequação à realidade econômica, social e cultural.

Técnicas processuais tradicionais e lineares passam a ser insuficientes e mostram-se pouco adequadas para a resolução efetiva das novas demandas. Direito fluidos e complexos exigem adaptação de procedimentos e condutas. Assim, pode-se notar que nem todo sistema processual civil está apto para acomodar as medidas estruturantes. Desta feita, o que se pretendeu demonstrar, no presente artigo, é que sistema processual civil brasileiro está apto para o emprego das decisões estruturantes.

O direito brasileiro demonstra abertura para a aplicação das medidas estruturantes, tanto em âmbito constitucional quanto na legislação infraconstitucional, não apenas nas hipóteses de litígios estratégicos ou de impacto, ou nas hipóteses em que a divergência quanto ao tema na sociedade é intensa, o que impediria uma solução única, pronta e acabada, mas também quando através do processo, busca-se a identificação das falhas estruturais nos mecanismos de outorga dos direitos fundamentais.

$\mathrm{O}$ acesso à justiça, constitucionalmente consagrado, e ainda a abertura interpretativa dada através das cláusulas gerais previstas no Código de Processo Civil de 2015 (BRASIL, 2015a), e de dispositivos infraconstitucionais, tais como o artigo 21 da Lei de Introdução às Normas do Direito Brasileiro (BRASIL, 1942), formam importante arcabouço para a adequação do processo estrutural ao direito brasileiro.

Ao erigir como modelo e princípio a colaboração, um dos pilares sob os quais se pauta o processo gerencial, passou-se a ter a participação e colaboração dos sujeitos processuais como essenciais à formação da decisão judicial, nota marcante do processo estrutural.

O artigo 21 da Lei de Introdução às Normas do Direito Brasileiro (BRASIL, 1942), por sua vez, estabelece como poder-dever ao magistrado a indicação das consequências jurídicas da decisão e a forma de efetivação equânime sem prejuízo dos interesses gerais, em uma clara referência à doutrina das medidas estruturantes.

Assim, conclui-se que, além do permissivo constitucional e da mudança do eixo epistemológico ocorrida com a abertura dada pelas cláusulas gerais, o direito brasileiro tem ainda dispositivos infraconstitucionais, que albergam e recomendam aplicação das medidas estruturantes como técnica de construção dos comandos decisórios. 


\section{REFERÊNCIAS}

ARENHART, Sérgio Cruz. Decisões estruturais no direito processual civil brasileiro. 2013. Disponível em: http://www.processoscoletivos.com.br/index.php/68-volume-6-numero-4trimestre-01-10-2015-a-31-12-2015/1668-decisoes-estruturais-no-direito-processual-civilbrasileiro. Acesso em: 29 abr. 2017.

ARENHART, Sérgio Cruz. Processo multipolar, participação e representação de interesses concorrentes. In: ARENHART, Sérgio Cruz; JOBIM, Marco Félix (org.). Processos estruturais. Salvador: Juspodivm, 2017. p. 423-448.

ARENHART, Sérgio Cruz. Processos estruturais no direito brasileiro: reflexões a partir do caso da ACP do carvão. Revista de Processo Comparado, [S. l.], v. 2, p. 211-232, 2015. Disponível em: http://revistadeprocessocomparado.com.br/wp-content/uploads/2016/01/ARENHARTSergio-Artigo-Decisoes-estruturais.pdf. Acesso em: 28 de abr. 2017.

BAUERMANN, Desirê. Cumprimento das obrigações de fazer ou não fazer: estudo comparado: Brasil e Estados Unidos. Porto Alegre: Sérgio Antonio Fabris Editor, 2012.

BELLINETTI, Luiz Fernando. Mandado de segurança coletivo: perspectiva conceitual e pressupostos de admissibilidade no direito positivo brasileiro. 1997. 285 f. Tese (Doutorado em Direito) - Pontifícia Universidade Católica de São Paulo, São Paulo, 1997.

BENEDUZI, Renato Resende. Comentários do código de processo civil: artigos 70 ao 187. São Paulo: Editora Revista dos Tribunais, 2016.

BRASIL. Decreto-Lei no 4.657, de 4 de setembro de 1942. Lei de introdução às normas do Direito Brasileiro. Brasília, DF: Presidência da República, 1942. Disponível em: http://www. planalto.gov.br/ccivil_03/decreto-lei/del4657.htm. Acesso em: 5 abr. 2017.

BRASIL. Lei no 13.105, de 16 de março de 2015. Código de Processo Civil. Brasília, DF: Presidência da República, 2015a. Disponível em: http://www.planalto.gov.br/ccivil_03/_ato20152018/2015/lei/113105.htm. Acesso em: 27 abr. 2017.

BRASIL. Lei no 13.655, de 25 de abril de 2018. Inclui no Decreto-Lei $n^{0} 4.657$, de 4 de setembro de 1942 (Lei de Introdução às Normas do Direito Brasileiro), disposições sobre segurança jurídica e eficiência na criação e na aplicação do direito público. Brasília, DF: Presidência da República, 2018. Disponível em: http://www.planalto.gov.br/ccivil_03/_ato20152018/2018/Lei/L13655.htm. Acesso em: 5 abr. 2019.

BRASIL. Supremo Tribunal Federal. AI681136. Relator: Min. Gilmar mendes. Julgado em 21 ago. 2008. Disponível em: http://www.stf.jus.br/portal/jurisprudencia/visualizarEmenta. asp?s1=000002473\&base=baseAcordaos. Acesso em: 27 abr. 2017.

BRASIL. Supremo Tribunal Federal. Petição 3.388. Reclamante: Augusto Affonso Botelho Neto. Requerido: União. Relator: Min. Ayres Britto. Roraima, 19 mar. 2019. Disponível em: http://redir.stf.jus.br/paginadorpub/paginador.jsp?docTP=AC\&docID=630133. Acesso em: 28 abr. 2019.

BRASIL. Supremo Tribunal Federal. Recurso Extraordinário 592.581 Rio Grande do Sul. 
Reclamante: Ministério Público do Estado do Rio Grande do Sul. Reclamado: Estado do Rio Grande do Sul. Relator: Min. Ricardo Lewandowski. Julgado em 13 ago. 2015b. Disponível em: http://redir.stf.jus.br/paginadorpub/paginador.jsp?docTP=TP\&docID=10166964. Acesso em: 27 abr. 2017.

CASTELO, Fernando Alcântara. Direito à saúde e decisões estruturais: por uma judicialização mais racional e eficiente. Revista de Processo, São Paulo, v. 274, n. 42, p. 317-342, 2017.

DIDIER JÚNIOR, Fredie; OLIVEIRA, Rafael Alexandria; ZANETI JÚNIOR, Hermes. Notas sobre as decisões estruturantes. In: ARENHART, Sérgio Cruz; JOBIM, Marco Félix (org.). Processos estruturais. Salvador: Juspodivm, 2017. p. 353-368.

FISS, Owen. Direito como razão pública: processo, jurisdição e sociedade. Tradução de Carlos Alberto de Salles. 2. ed. Curitiba: Juruá, 2017.

FISS, Owen. The forms of justice. Harvard Law Review, Cambridge, n. 93, 1979.

FRANCO, Marcelo Veiga. Dimensão dinâmica do contraditório, fundamentação decisória e conotação ética do processo justo: breve reflexão sobre o art. $489, \S 1^{\circ}$, IV, do novo CPC. Revista de Processo, São Paulo, v. 247, n. 40, p. 105-136, set. 2015.

JOBIM, Marco Félix. Medidas estruturantes: da suprema corte estadunidense ao supremo tribunal federal. Porto Alegre: Livraria do Advogado Editora, 2013.

MARINONI, Luiz Guilherme. As novas sentenças e os novos poderes do juiz para a prestação da tutela jurisdicional efetiva. In: DIDIER JÚNIOR, Fredie (org.). Processo civil: leituras complementares. 4. ed. Salvador: JusPodivm, 2006.

MARINONI, Luiz Guilherme; MITIDIERO, Daniel. Comentários do código de processo civil: artigos $1^{\circ}$ ao 69. São Paulo: Editora Revista dos Tribunais, 2016.

MORO, Sérgio Fernando. Jurisdição constitucional como democracia. São Paulo: Editora Revista dos Tribunais, 2004.

NERY JÚNIOR, Nelson; NERY, Rosa Maria Andrade. Código de processo civil e legislação processual civil extravagante em vigor. 12. ed. São Paulo: RT, 2017.

NEVES, Daniel Amorim Assumpção. Novo código de processo civil comentado artigo por artigo. Salvador: Editora Juspodivm, 2016.

NUNES, Dierle. Precedentes, padronização decisória preventiva e coletivização - paradoxos do sistema jurídico brasileiro: uma abordagem constitucional democrática. In: WAMBIER, Teresa Arruda Alvim (coord.). Direito jurisprudencial. São Paulo: Revista dos Tribunais, 2012. p. 245276.

PINTO, Henrique Alves. O enquadramento das decisões estruturais no novo código de processo civil. Revista de Processo, São Paulo, v. 271, n. 42. p. 369-402, set. 2017.

VINCENZI, Brunela; ALVES, Gustavo Silva; REZENDE, Priscilla Correa Gonçalves de. As ações coletivas como espécie de litígio estratégico: um diálogo com a luta social por reconhecimento de Axel Honneth. Direito \& Paz, São Paulo, Ano XVIII, n. 34, p. 209-236, 
2016.

ZIPPELIUS, Reinhold. Teoria geral do estado. Tradução de Karin Praefke-Aires Coutinho. 3. ed. Lisboa: Fundação Calouste Gulbenkian, 1997.

Como citar: JAURIS, Renata Bolzan; BELLINETTI, Luiz Fernando. As medidas estruturantes e a compatibilidade com o direito processual brasileiro. Scientia Iuris, Londrina, v. 24, n. 2, p. 6480, jul. 2020. DOI: 10.5433/2178-8189.2020v24n2p64. ISSN: 2178-8189.

Recebido em: 04/11/2019

Aprovado em: 09/04/2020 